References:

[1] DOI:10.1371/journal.pone.0127012

Disclosure of Interests: None declared

DOI: 10.1136/annrheumdis-2020-eular.5927

\section{AB1316-HPR COMORBIDITIES IMPACT ON PHYSICAL REHABILITATION PROGRAM OUTCOMES IN PATIENTS WITH KNEE OSTEOARTHRITIS}

V. Salaru' ${ }^{1}$, A. Vizdoaga ${ }^{2}$, L. Mazur-Nicorici ${ }^{3}$, M. Cebanu ${ }^{4}$, T. Rotaru ${ }^{5}$, S. Vetrila ${ }^{3}$, M. Garabajiu ${ }^{3}$, N. Loghin-Oprea ${ }^{3}$, V. Sadovici-Bobeica ${ }^{3}$, M. Mazur $^{3} .{ }^{1}$ State University of Medicine and Pharmacy "Nicolae Testemitanu", Family Medicine, Chișinău, Moldova, Republic of; ${ }^{2}$ University Medical Rehabilitation Center, Medical Rehabilitation, Physical and Manual Therapy, Chișinău, Moldova, Republic of; ${ }^{3}$ State University of Medicine and Pharmacy "Nicolae Testemitanu", Internal Medicine, Chișinău, Moldova, Republic of; ${ }^{4}$ State University of Medicine and Pharmacy "Nicolae Testemitanu", Emergency Medicine, Chișinău, Moldova, Republic of; ${ }^{5}$ Institute of Cardiology, Chișinău, Moldova, Republic of

Background: Physical rehabilitation is proposed as a method of non-pharmacological treatment of knee osteoarthritis $(\mathrm{OA})$ by the EULAR and OARSI recommendations. At the same time, presence of concomitant diseases could influence the condition of patients and the outcomes of the rehabilitation program.

Objectives: To evaluate the frequency of comorbidities in OA patients and to appreciate their impact on outcomes of the physical rehabilitation program.

Methods: A prospective control case study was conducted in the University Rehabilitation Center. The patients underwent clinical examination, VAS scale was used to assess level of pain, and Knee Injury and Osteoarthritis Outcome Score (KOOS) with 5 domains (Pain, Symptoms, ADL, Sport, QoL) for joint function assessment. These parameters were evaluated at the onset of the program (T0) and at the end of the 10th day (T1). Medical data records, general clinical exam and Charlson Comorbidities Index $(\mathrm{CCl})$ assessed the comorbidities.

Results: 48 patients with OA were included in the study, 37 patients of them were found with comorbidities. The most frequent associated diseases were: cardiovascular- $76.6 \%$, obesity- $59.9 \%$, and endocrine - $12.9 \%$ cases. At T0, significantly lower levels in the group with comorbidities were identified on the domains Pain, Sport and QoL. The CCl in patients with comorbidities was $3.29 \pm 0.14$ points $(82.1 \%$ for 1 -year survival rate). At the T1 moment, we found an improvement in joint functionality in both groups. The mean value of the VAS score group of patients without comorbidities decreased from $48,18 \mathrm{~mm}$ to $21,36 \mathrm{~mm}$ $(p<0.05)$ and for the group of patients with comorbidities $-64,2$ at $/ 36,2 \mathrm{~mm}$ $(p<0.001)$. Significant improvement in joint function in the comorbidities group was in Pain $(p<0.01)$, Sport $(p<0.05)$ and Qol $(p<0.01)$ domains, at the same in patients without comorbidities, the improvement was significant in all 5 domains. Conclusion: Comorbidities are highly associated to knee osteoarthritis and prove to have a negative influence on the results of the physical rehabilitation program; therefore, we would recommend to apply individualized rehabilitation programs adapted to the associated conditions of each patient.

Disclosure of Interests: None declared

DOI: 10.1136/annrheumdis-2020-eular.2725

\section{AB1317-HPR YOGA-THERAPY: IMPROVEMENT IN PSORIATIC ARTHRITIS PROMS AT 4 MONTHS}

C. B. Colaco ${ }^{1}$, V. Sadana ${ }^{2}$, K. Anie ${ }^{2} .{ }^{1}$ LNWUH NHS Trust, CMH Rheumatology Unit, London, United Kingdom; ${ }^{2}$ LNWUH NHS Trust, CMH Rheumatology Unit, London, United Kingdom

Background: Psoriatic Arthritis and Psoriasis have a major impact on QOL with associated mood disorders and Cardiovascular disease and Cancer as inter-related co-morbidities ${ }^{1}$. Yoga therapy ( $\left.\mathrm{Y}-\mathrm{T}\right)$ has been used in several Long Term Conditions ${ }^{2}$ and we have reported Rapid improvement in Proms in RA (RCP 2018) and so compared results of a PsA cohort offered the same Y-T intervention. Objectives: This first in UK PsA study investigated: a) impact of a 16 week Y-T intervention on functional outcomes and QOL in 10 PsA patients, b) acceptability and experiences of the intervention. We present results in comparison to a previously reported RA cohort $n=10$.

Methods: Ten adult PsA patients (2 M 8 F Age 32-67 Avg: 53.7 Y; PsA diagnosis: $6.45 \mathrm{yrs:} 1$ Juvenile onset) consented to 10 individual Y-T sessions (weekly $\times$ 4; biweekly $\times 6$ ) with a yoga therapist in a standard consulting room. The intervention was tailored to the needs and abilities of each patient and included: breath-centered physical yoga postures, breathing and visualization techniques, mantras and meditation, with supportive Lifestyle/behavioural strategies. All participants completed measures pre- and post-intervention (EQ-5D HAQ HADS $P G I C)$ to assess change in health status.

Results: A 10 session course of $\mathrm{Y}$-T over 16 weeks was completed with 92/100 PsA YT sessions. Note 1 patient had unrelated Trauma and withdrew after 2 sessions. This confirms acceptability of delivery in a clinic setting and all participants reported strong adherence to practices (0-1) and strong belief (0-2) in impact of yoga. (Likert 5 point 0-4 scale).

Further data on only 9 PsA participants will be presented in comparison to the previous RA cohort of 10 .

PsA patients n=9: Pain reduced $25 \%$ HADs Depression reduced 39\% Anxiety reduced $25 \%$

$\mathrm{HAQ}$ health score improvement was significant at $\mathrm{P}<0.04$ (ANOVA).

EQol $5 \mathrm{~d}(3 \mathrm{~L})$ improved $24 \%$ but overall $\mathrm{QOL}$ remained below $50 \%$ max calculated TTO.

RA patients had recorded stable overall TTO at a higher level 0.63 pre and post Y-T.

PGIC record of positive change is recorded as a reduction on VAS from $5 / 5$ to $2.4 / 5$

We will add 12 month FU data set in PsA to compare with 24 month data in the RA cohort.

Conclusion: Yoga-Therapy is deliverable and acceptable in a NHS clinic setting for PsA. Improved PROMS begs further larger studies of mechanisms of bio-psychosocial intervention in long term inflammatory conditions. The outcomes support the Poly Vagal Theory ${ }^{3}$ as an effector model, via the bio-mechanistic neuro-inflammatory reflex ${ }^{4}$. We propose further Health Economic analysis of this $2500 \mathrm{yr}$ old Yoga model for long term conditions to examine any long term cost benefit to the NHS.

References:

[1] Coates LC et al Rheumatology 2018;57:1321-1331 Remission in psoriatic arthritis-where are we now?

[2] Khalsa, SB, Cohen, L, McCall, T \& Telles, S (2016) (Eds). The Principles and Practice of Yoga in Health Care. Handspring Publishing.

[3] Sullivan M B Porges SW et alFront. Hum. Neurosci., 2018 Yoga Therapy and Polyvagal Theory: The Convergence of Traditional Wisdom and Contemporary Neuroscience for Self-Regulation and Resilience

[4] Pavlov V Tracey K Nat Rev Endocrinol. 2012 Dec; 8(12): 743-754. The vagus nerve and the inflammatory reflex-linking immunity and metabolism

Table 1. PsA vs RA post Yoga Therapy PROMs at $4 \mathrm{mth}$.

PsA $n=9$ PsA 4 mPsA 4 m \%RA $n=10$ PreRA4m FU RA $4 m \%$ pre

HADS m Depression

HADS m Anxiety

Mean $\mathrm{HAQ}$
M Pain Score (HAQ)

$M$ Health Score (HAQ)

$\mathrm{M}$ H Utility TTO (EQol5d)

PGIC

\begin{tabular}{|c|c|c|c|c|c|}
\hline 6.33 & 3.88 & -39 & 6.7 & 2.3 & -65 \\
\hline 8.56 & 6.44 & -25 & 9.4 & 4.8 & -48 \\
\hline 0.79 & 0.75 & -2 & 0.78 & 0.48 & -26 \\
\hline 60 & 45.00 & -25 & 57 & 24 & -58 \\
\hline 60 & 42.7 & $-29 p<0.04$ & 51 & 17.2 & -66 \\
\hline 0.4 & 0.5 & +24 & 0.63 & 0.63 & 0 \\
\hline
\end{tabular}

Acknowledgments: CMH Rheumatology Support Group

Disclosure of Interests: C Bernard Colaco Grant/research support from: Trave Support for Conference attendance, Speakers bureau: Menarini, Vidhi Sadana: None declared, Kofi Anie: None declared

DOI: 10.1136/annrheumdis-2020-eular.5968

\section{AB1318-HPR VAGUS NERVE STIMULATION IN PATIENTS WITH RHEUMATOID ARTHRITIS: 48 MONTH SAFETY AND EFFICACY}

F. Koopman ${ }^{1}$, A. Musters ${ }^{2}$, M. Backer ${ }^{2}$, D. Gerlag ${ }^{2}$, S. Miljko ${ }^{3}$, S. Grazio ${ }^{4}$, S. Sokolovic ${ }^{5}$, Y. Levine ${ }^{6}$, E. Glass ${ }^{6}$, D. Chernoff ${ }^{6}$, N. De Vries ${ }^{2}$, P. P. Tak ${ }^{2}$. ${ }^{1}$ Academic Medical Center/University of Amsterdam, Amsterdam, Netherlands; ${ }^{2}$ University of Amsterdam, Amsterdam, Netherlands; ${ }^{3}$ University Clinical Hospital, Mostar, Bosnia and Herzegovina; ${ }^{4}$ Clinical Hospital Center Sestre Milosrdnice, Zagreb, Croatia; ${ }^{5}$ Sarajevo University Clinical Center, Sarajevo, Bosnia and Herzegovina; ${ }^{6}$ SetPoint Medical, Valencia, United States of America

Background: Rheumatoid arthritis (RA) is a disease with significant remaining unmet medical needs for better treatments. Vagus nerve stimulation (VNS) to activate the inflammatory reflex (cholinergic anti-inflammatory pathway) represents a novel experimental therapy for RA. ${ }^{1}$ Previously, we reported that inflammatory reflex activation by VNS reduced pro-inflammatory cytokine production and improved disease activity in a 17-patient rheumatoid arthritis (RA) proof-ofconcept study using a reprogrammed epilepsy stimulator2; clinical improvement was sustained for 24 months without untoward safety signals. ${ }^{3}$ Here we report the 48 months results from this long-term observational study.

Objectives: Determine the long-term safety and efficacy of VNS for the treatment of RA

Methods: In the primary study, a VNS device was implanted into 17 RA patients, mostly with insufficient response to multiple conventional and biologic DMARDs on stable background of methotrexate ( $\leq 25 \mathrm{mg}$ weekly) therapy ${ }^{2}$. The device electrically stimulated the vagus nerve, $1-4 \mathrm{~min} /$ day, over a 12 -week open label 
period. On completion, subjects were offered to enroll into a follow-up study, where the study physicians were given flexibility to alter VNS dosing parameters and/or to add a biologic disease-modifying antirheumatic drug (DMARD) to the treatment regimen to induce disease remission. Clinical disease activity measures and safety were accessed over 4 years.

Results: All patients electively continued VNS treatment in the long-term follow-up study, 4 subjects withdrew prior to month 48 . Reasons for discontinuation were withdrawal of consent $(\mathrm{N}=3)$ and adverse event due to device discomfort $(\mathrm{N}=1)$. At the start of the follow-up study, the mean DAS28-CRP, CDAI and HAQ-DI were significantly reduced compared to the pre-implant baseline (mean difference $\pm S D$ : DAS28-CRP $=-1.60 \pm 1.13, p<0.001 ; C D A l=-21.19 \pm 13.5, p<0.001 ; \mathrm{HAQ}-\mathrm{Dl}=-0.44 \pm$ $0.49, p<0.01$ ), and this effect was retained through 48 months. Patients using VNS monotherapy and those using a combination of VNS with biologic DMARDs exhibited stable improvements in DAS28-CRP, CDAI and HAQ-DI at month 48 (Table 1). Improvements were observed for patients who both previously had an insufficient response to targeted biological therapies as well those who had an insufficient response to standard DMARDs. No association was seen between DAS28-CRP and stimulation frequency (Range $=1 \mathrm{X}-8 \mathrm{X} /$ day). There was no difference in the adverse events profile between the two groups.

Table 1. Efficacy of VNS treatment.

\begin{tabular}{|c|c|c|c|c|c|c|c|c|c|}
\hline & \multicolumn{3}{|c|}{$\begin{array}{c}\text { Treatment Reinitiated } \\
\qquad \mathrm{N}=9\end{array}$} & \multicolumn{3}{|c|}{$\begin{array}{l}\text { VNS Monotherapy } \\
\qquad \mathrm{N}=8\end{array}$} & \multicolumn{3}{|c|}{$\begin{array}{l}\text { Total } \\
\mathrm{N}=17\end{array}$} \\
\hline & Mo. 24 & Mo. 36 & Mo.48 & Mo. 24 & Mo. 36 & Mo. 48 & Mo. 24 & Mo. 36 & Mo. 48 \\
\hline \multicolumn{10}{|c|}{ Mean change from baseline (SD) } \\
\hline \multirow[t]{2}{*}{ DAS28-CRP } & -2.58 & -2.40 & -2.28 & -2.61 & -1.77 & -2.0 & -2.59 & -2.19 & -2.17 \\
\hline & $(1.0)^{\star \star \star}$ & $(1.0)^{\star *}$ & $(1.3)^{\star *}$ & $(1.3)^{*}$ & $(1.8)$ & (1.7) & $(1.1)^{\star \star \star}$ & $(1.2)^{\star \star}$ & $(1.4)^{\star *}$ \\
\hline \multirow[t]{2}{*}{ CDAI } & -24.06 & -18.02 & -16.2 & -33.5 & -27.8 & -27.9 & -28.20 & -21.93 & -20.83 \\
\hline & $(8.3)^{\star \star \star}$ & * $(13.3)^{*}$ & * (19.6) & $(11.1)^{\star \star *}$ & $(16.0)^{\star}$ & $(12.7)^{\star}$ & $(10.5)^{\star \star \star}$ & $(14.5)^{\star}$ & $(17.5)^{\star}$ \\
\hline \multirow[t]{2}{*}{ HAQ-DI } & -.60 & -.63 & -.31 & -.89 & -.88 & -.88 & -0.73 & -0.73 & -0.54 \\
\hline & $(0.64)^{\star}$ & $(0.45)^{\star}$ & $(0.60)$ & $(0.69)^{\star}$ & $(0.92)$ & $(0.61)$ & $(0.66)^{\star \star \star}$ & $(0.64)^{\star \star}$ & ${ }^{*}(0.64)^{\star}$ \\
\hline
\end{tabular}

${ }^{\star} \mathrm{P}<0.05,{ }^{* \star} \mathrm{P}<0.01,{ }^{* \star *} \mathrm{P}<0.001$ versus primary study baseline (month -3.5 )

Conclusion: VNS was safe, well-tolerated, and resulted in significant and clinically important improvements in disease activity measures that were maintained over 48 months. These results support development of VNS devices as a new therapeutic option for RA treatment.

References:

[1] van Maanen MA, et al. Nat Rev Rheum 2009

[2] Koopman FA, et al. PNAS 2016

[3] Koopman FA, et al. Arthritis Rheum 2018

Disclosure of Interests: Frieda Koopman: None declared, Anne Musters: None declared, Marieke Backer: None declared, Danielle Gerlag Shareholder of: GlaxoSmithKline, Employee of: GlaxoSmithKline, Sanda Miljko: None declared, Simeon Grazio Speakers bureau: Abbvie., Roche, MSD, Eli Lilly, Pfizer, Mylan, Amgen, Fresenius Kabi, Stada, Berlin-Chemie, Sekib Sokolovic: None declared, Yaakov Levine Shareholder of: SetPoint Medical, Employee of: SetPoint Medical, Emmett Glass Employee of: SetPoint Medical, David Chernoff Shareholder of: SetPoint Medical, Adamas Pharmaceuticals, Olly Nutrition, NAIA Pharma, Aquinox Pharma, Consultant of: Adamas Pharmaceuticals, Olly Nutrition, NAIA Pharma, Aquinox Pharma, Crescendo Bioscience, Employee of: SetPoint Medical, Niek de Vries Grant/research support from: AbbVie, Janssen, Ergomed Clinical Research, GlaxoSmithKline, Pfizer, Boehringer Ingelheim, Roche, Consultant of: MSD, Pfizer, Paul P. Tak Shareholder of: GlaxoSmithKline, Employee of: GlaxoSmithKline DOI: 10.1136/annrheumdis-2020-eular.2914

\section{AB1319-HPR EFFECT OF SEGMENTAL STABILIZATION AND PILATES ON CHRONIC NON-SPECIFIC LOW BACK PAIN: PILOT STUDY}

A. Torres $\mathrm{Cruz}^{1}$, P. De Oliveira Januário ${ }^{1}$, I. Coelho Baptista ${ }^{2}$, A. Da Rocha Rodrigues $^{2}$, C. H. Chagas Bernardo ${ }^{2}$, T. Silva Nunes ${ }^{2}$, M. Antunes ${ }^{1}$, I. Merllin Batista de Souza' ${ }^{1}$ A. Pasqual Marques ${ }^{1} .{ }^{1}$ Universidade de São Paulo, Department of Physical Therapy Speech Therapy and Occupational Therapy, São Paulo, Brazil; ${ }^{2}$ Centro Universitário de Barra Mansa, Department of Physical Therapy, Barra Mansa, Brazil

Background: Low back pain is an important health condition with major socioeconomic consequences and is associated with high costs for the health system, absenteeism at work and reduced functional performance. It is one of the most relevant health problems in the elderly, with point prevalence estimates higher than other musculoskeletal conditions.

Objectives: To verify the effect of segmental stabilization versus the Pilates method in the elderly with chronic low back pain.
Methods: The study included 9 elderly women with chronic low back pain randomized into two groups: Segmental Stabilization Group (SG $n=5$; age $65.2 \pm 4.32$ Body Mass Index - BMI $29.99 \pm 4.65$ ) and Pilates Group (PG $n=4$; age $67.75 \pm 7.13$ $\mathrm{BMI} 26.49 \pm 4.06)$. Both groups underwent 16 individual sessions of 60 minutes twice a week and avaliated before and after 8 weeks. Pain was assessed using the Visual Analogue Pain Scale; functional disability, by Oswestry's disability index; excessive fear of movement and physical activity, using the Tampa Kinesiophobia Scale; level of confidence in the balance for specific activities, on the Activity-Specific Balance Confidence $(A B C)$ scale and; activation of the transverse muscle of the abdomen, by the pressure biofeedback unit Stabilizer of the Chatanooga brand. The allocation and evaluations of the participants were performed by a blind examiner. The data were analyzed using the Student's t-test with the level of significance $(p \leq 0.05)$.

Results: The data show significant differences in the reduction of pain intensity $(p=0.022)$ and functional disability $(p=0.023)$ only in SG and improvement in kinesiophobia ( $p=0.007$ ) only in $P G$. The level of confidence in the balance for specific activities was better in the SG when compared to the $P G(p=0.059)$. There was no difference in the activation of the transversus abdominis in both groups.

Conclusion: The results indicate that the segmental stabilization was effective to improve pain and functional disability, Pilates to improve the degree of kinesiophobia and the SG obtained a better result when compared to the PG regarding the level of confidence in the balance for specific activities. Both techniques had a great effect on improving functional capacity and on the level of confidence in the balance for specific activities. It is suggested to carry out studies with a large number of participants and follow-up evaluation to assess the long-term effects. References:

[1] Boonstra AM, Preuper HRS, Reneman MF, Posthumus JB, Stewart RE. Reliability and validity of the visual analogue scale for disability in patients with chronic musculoskeletal pain. IJSR 2008; 3(2):165-9.

[2] Marques AP, Mendes YC, Taddei U, Pereira CAB, Assumpção A. Brazilian-Portuguese translation and cross cultural adaptation of the activities-specific balance confidence ABC) scale. Braz J Phys Ther 2013; 17(2): 170-8.

[3] Siqueira FB, Teixeira-Salmela LF, Magalhães LC. Análise das propriedades psicométricas da versão brasileira da escala tampa de cinesiofobia. Acta Orto Bras 2007; 15(1): 19-24.

[4] Viggato R, Alexandre NMC, Correa Filho HR. Development of a Braziliam Portuguese version of the Oswestry Disability Index: cross-cultural adaptation, reliability, and validity. Spine 2007; 32(4):481-6.

Acknowledgments: Coordenação de Aperfeiçoamento de Pessoal de Nível Superior (CAPES)

Disclosure of Interests: None declared

DOI: 10.1136/annrheumdis-2020-eular.3371

\section{AB1320-HPR THE ASSOCIATION BETWEEN PHYSICAL ACTIVITY AND CARDIORESPIRATORY FITNESS IN PATIENTS WITH RHEUMATOID ARTHRITIS AND HIGH CARDIOVASCULAR RISK}

J. Van den Hoek ${ }^{1}$, M. Van der Leeden², G. Metsios ${ }^{3}$, G. Kitas ${ }^{4}$, H. Jorstad ${ }^{2}$, W. Lems ${ }^{2}$, M. Nurmohamed ${ }^{2}$, M. Van der Esch ${ }^{5} .{ }^{1}$ Amsterdam Rehabilitation Research Center| Reade, Amsterdam, Netherlands; ${ }^{2}$ Amsterdam University Medical Centers, Amsterdam, Netherlands; ${ }^{3}$ University of Wolverhampton, West Midlands, United Kingdom; ${ }^{4}$ Russel's Hall Hospital, West Midlands, United Kingdom; ${ }^{5}$ Amsterdam Rehabilitation Research Center | Reade, Amsterdam, Netherlands

Background: Rheumatoid arthritis (RA) is associated with increased risk of cardiovascular disease (CVD) disease and CV mortality ${ }^{1}$. High values of cardiorespiratory fitness (CRF) are protective against CVD and CV mortality ${ }^{2}$. Physical activity levels in patients with RA are low. Knowledge on whether physical activity is associated with CRF in patients with RA and high CV risk is scarce. This knowledge is important because improving the level of physical activity could improve CRF and lower CV risk in this group of patients with RA and high CV risk. However, it is unclear whether physical activity is associated with CRF in this group of patients. This study presents the preliminary results at baseline of the association of physical activity with CRF from an ongoing pilot study aimed at improving CRF through exercise therapy in patients with RA and high CV risk. Objectives: To determine (i) the level of physical activity in patients with RA and high CV risk and (ii) whether physical activity is associated with CRF in patients with RA and high $\mathrm{CV}$ risk.

Methods: Patients with RA and high CV risk participated in this pilot study. Increased 10-year risk of CV mortality was determined by using the Dutch SCORE-table. Anthropometrics and disease characteristics were collected. Physical activity was assessed with an Actigraph accelerometer to determine the number of steps and intensity of physical activity expressed in terms of sedentary, light, and moderate-to-vigorous time per day. Participants wore the acceler ometer for seven days. A minimum of four measurement days with a wear time of 